\title{
SOBRE LA FUNCIÓN PROMOCIONAL DEL DERECHO. UN ANÁLISIS CONCEPTUAL
}

\author{
Juan Antonio Pérez Lledó
}

Universidad de Alicante

\section{Introducción}

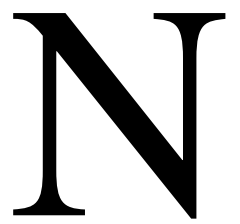

o sé hasta qué punto será acertada mi impresión de que la reflexión sobre la función promocional del Derecho ha «perdido fuerza» en la teoría del Derecho de los últimos años; al menos creo que sí se puede afirmar tal cosa si tomamos como referencia el «momento dulce» que vivió ese objeto de estudio durante los años setenta y comienzos de los ochenta, cuando diversos trabajos de Bobbio llamaron la atención y suscitaron el debate sobre la relevancia de esa «nueva» (o más bien «recuperada») función del Derecho. No es mi intención discutir aquí ni las causas ni la justificación o no de ese menor interés. Sólo diré -argumentarlo me llevaría muy lejosque en mi opinión hay buenas razones, intelectuales y políticas, para que los iusfilósofos volvamos a considerar la llamada vertiente «premial» del Derecho como un tema central sobre el que trabajar.

Una reivindicación de este tipo seguramente resulta menos convincente cuando quien la formula no ha predicado antes con el ejemplo. Y ése es mi caso. El origen de esta «Nota»-solo es eso, una nota- no es un concienzudo trabajo previo sobre la (con todo, muy abundante) literatura disponible acerca de la función promocional del Derecho. Yo andaba en otras cosas, y me puse a escribir lo que al final se ha convertido en las páginas que siguen simplemente para poner un poco de orden en el aluvión de ideas que informalmente surgieron en un despacho, el de mi compañero Josep Aguiló, cuando ambos discutíamos el borrador de un capítulo de tesis doctoral con su autor, Roberto Lara. Ese capítulo trataba del concepto de sanción en Bobbio, y en la discusión sobre el mismo los tres estábamos de acuerdo en la necesidad de aclarar y «reconstruir» algunas distinciones conceptuales apuntadas por Bobbio (y discutidas por otros autores) a propósito de la función promocional y las sanciones positivas. Eso intento hacer en esta Nota. 
Etiquetarla como una «reconstrucción o propuesta» es de una ambigüedad deliberada. Hasta qué punto lo que aquí presento es una propuesta verdaderamente «novedosa» o por el contrario mucho de lo que se dice estaba ya, en alguna medida, en el mismo Bobbio o en otros autores, es algo que dejo para el especialista en función promocional del Derecho que desee realizar un trabajo filológico comparando éste con otros escritos. O lo dejo para mí mismo, para una futura versión más «académica» de este trabajo en el que se expliciten las referencias bibliográficas aquí omitidas, se presente previamente un «estado de la cuestión» y se entre a discutir con otros autores. Esta nota sólo pretende ser un «ensayo» escrito a tumba abierta donde se recoge únicamente la pars construens. Se diseña un esquema de distinciones conceptuales tal y como uno las ha pensado directamente: una nota sin apenas notas, sin demasiadas preocupaciones sobre si lo dicho estaba ya dicho y/o en qué medida se aparta de o es una crítica a otros ${ }^{1}$.

\footnotetext{
${ }^{1}$ Me interesa destacar esto sobre todo porque el punto de partida ha sido, como he dicho, refinar (o aclarar, o reconstruir, o completar y -por qué no- corregir) ciertas distinciones conceptuales de Bobbio; y, claro, si eso se entiende como «enmendar la plana» nada menos que a Bobbio, y más aún en el terreno de las distinciones conceptuales, parecerá una osadía que, de entrada, requeriría bastantes páginas sobré qué había dicho Bobbio y en qué sigue o se aparta uno de él. Olvidémonos un poco de Bobbio y de si hago más crítica o más seguidismo de él, y vayamos a si funciona o no el esquema que presento. Por lo demás, creo que, aunque resulte llamativo, en el terreno que aquí nos ocupa, el de las específicas técnicas promocionales, Bobbio no se preocupó tanto como en otros temas por perfilar y desarrollar cuidadosamente un cuadro conceptual sistemático (aunque no dejara de trazar distinciones, y hablara -como haré yo aquí, pero modificando su significado- de premios, incentivos y facilitaciones). Probablemente, porque en realidad lo que más le interesaba sobre la función promocional no era el análisis conceptual. El propio Bobbio era consciente de que él dejaba trabajo analítico por desarrollar. A propósito de $s u$ distinción entre premios e incentivos, escribió: «Queda el problema que suscita esta distinción, por más o menos válida que sea, y que merecería ser profundizado quizá más que el problema esencialmente terminológico sobre el uso y abuso del concepto de función o sobre la existencia o no de una correspondencia entre las funciones y las técnicas. Se trata de afrontar, de ahora en adelante, una investigación analítica de todas las técnicas de alentamiento que son -y sobre ello estamos todos de acuerdo- una de las características del Estado contemporáneo, con el mismo cuidado por los aspectos particulares con que se ha llevado a cabo durante siglos el análisis de las medidas represivas. No sé si una investigación de ese tipo está aún por hacer (...). Sin duda, de la recogida de datos mediante investigaciones empíricas puede enriquecerse y perfeccionarse la tipología de las referidas medidas, y así alimentarse y orientarse mejor el debate sobre el derecho premial» (BOBBIO, Norberto, «La funzione promozionale del diritto rivisitata», Sociologia del diritto, 1984, núm. 3, p.26-27). Este trabajo pretende ser una contribución a esa investigación analítica a la que el propio Bobbio invitaba al despedirse él de este tema.
} 


\section{Planteamiento: fines a promocionar y medios promocionales}

No todas las medidas promocionales promocionan las mismas cosas (¿conductas? ¿estados de cosas y/o valores?), ni todas utilizan las mismas técnicas, ni «promocionan por igual». Es decir, debemos distinguir entre el fin a promocionar y las técnicas o medios promocionales; y distinguir, entre éstos, aquellos que consisten en incentivar (motivar) conductas de aquellos que no consisten en motivar directamente la conducta (sino, simplemente, en posibilitarla o en premiarla). Propongo para ello distinguir cuatro conceptos básicos: premio puro, promesa de premio, incentivo puro y facilitación. Pero antes, una distinción conceptual previa, y una estipulación terminológica.

Cuando hablamos, en general, del «Derecho premial» o de la función promocional del Derecho, el objeto perseguido, promovido, favorecido, etc., al que nos estamos refiriendo puede ser:

a) Fines generales: es decir, bienes jurídicos, que serán «estados de cosas» $\mathrm{o}$ «valores» (a veces, simplemente «virtudes») considerados deseables por el Derecho, ya sea por razones de utilidad (son socialmente beneficiosos) o por razones «de principio» (son en sí mismos valiosos). Por ejemplo, los fines (normalmente de carácter social, económico, cultural, etc.) que persiguen las «directrices» o policies constitucionales; o los valores (de libertad, igualdad, justicia, etc.) que típicamente se expresan mediante «principios» en sentido estricto (obviamente, también subyacen valores a las directrices); o ciertas virtudes cívicas que simplemente se consideran encomiables a la luz de esos fines o valores.

b) Conductas (o clases de conductas) particulares: cursos de acción que se consideran deseables, $\mathrm{o}$ al menos valorados positivamente.

Las conductas, si se consideran deseables y por tanto objeto de algún tipo de favorecimiento (premio como puro reconocimiento, promesa de premio, incentivación, o facilitación), es por su vinculación con ciertos fines (estados de cosas o valores) generales deseables. Propongo por tanto que veamos los bienes y valores señalados en $a$ ) como los fines u objetivos a promocionar indirectamente; y reservar, respecto de ellos, las palabras «promoción», «promocionar», «función promocional», etc. Y que veamos el favorecimiento de conductas señaladas en $b$ ), o sea, las medidas de diverso tipo que operan directamente sobre determinadas conductas o determinadas clases de conductas, como técnicas o medios para promocionar aquellos fines; y reservar, en cuanto predicadas de estas conductas como su objeto, palabras como «incentivación», «motivación» o «alentamiento», pero no «promoción». Aunque «promocional» ha de ser el adjetivo de las técnicas cuando en general nos referimos a ellas en sí mismas (la idea de téc- 
nica está vinculada al fin para el que es medio, y ese fin se «promociona» como objetivo y en su caso resultado global), cuando hablamos de lo que esas técnicas «hacen» en concreto para promocionar esos fines, operando sobre conductas, quizá sería mejor usar esas otras palabras (para evitar confusiones y mantener clara esta distinción). En suma: se «promocionan» indirectamente ciertos fines (estados de cosas o valores), y para ello se utilizan ciertas «técnicas promocionales» que operan directamente sobre conductas, por ejemplo «motivándolas».

El interés de mi análisis, una vez preparado así el camino, radica en distinguir conceptualmente al menos cuatro de esas «técnicas promocionales». Y en mostrar cómo, operando las cuatro sobre o respecto de conductas, sólo dos de ellas (la «promesa de premio» y el «incentivo») operan «motivándolas» (suministrando razones operativas para la acción); mientras que las otras dos (el «premio puro» y la «facilitación») carecen de ese aspecto, conservando no obstante, aunque de modo mucho más débil, su virtualidad de «técnica promocional» favorecedora, en algún sentido, de estados de cosas o valores.

Dos observaciones más que corresponde explicitar ya en este «planteamiento», aunque volverán a aparecer más adelante: 1) El criterio aquí utilizado para distinguir las técnicas promocionales es «funcional» sólo en el sentido de que es el de la finalidad o intención del legislador o «dador» de la medida (la función social que él persigue), y no en el de cómo ésta opera de hecho en la mente de los destinatarios (algo seguramente más difícil de determinar); ni tampoco en el de cuál sea la función social que empíricamente se cumple en cuanto al logro real de los resultados, tanto de los inmediatos relativos a la realización efectiva de las conductas como de los mediatos relativos a la eficaz promoción de fines globales (algo también más difícil de determinar aunque seguramente de mayor interés); es más que probable que una conceptualización siguiendo esos otros criterios arrojara resultados distintos, pero eso sería ya un trabajo diferente -estaría bien realizarlo- del que he pretendido hacer aquí 2 2) Las que distinguiré son «cate-

\footnotetext{
${ }^{2}$ Valga en mi descargo, para quien insista en el mayor interés -desde luego, sociológicode los otros criterios (cosa que no discuto), que ello no anula el interés que también tiene el criterio aquí adoptado; por ejemplo, sin ir más lejos, no hace falta ser un fanático del instrumento teleológico para reconocer alguna relevancia a mi criterio a los efectos de la interpretación jurídica de las normas con que se adoptan estas medidas. Por lo demás, este criterio no es distinto del que tradicionalmente se sigue cuando se distingue, en el ámbito de las sanciones negativas, entre sus «funciones» retributiva, preventiva (general y especial), resocializadora, etc.: aunque estas funciones pueden verse desde los otros puntos de vista, no es menos cierto que también (quizá sobre todo) suelen entenderse desde el de la finalidad buscada por el legislador. Y otra cosa: mi criterio no pretende tomar partido en la vieja discusión entre subjeti-
} 
gorías» situadas en un nivel conceptual y, en principio, no aspiran a permitir clasificar las medidas promocionales que de hecho existen en nuestros ordenamientos jurídicos, ya que esos rasgos conceptuales aparecen a menudo combinados en la realidad jurídica en formas a menudo muy complejas; no por ello mi distinción se convierte en inútil, ya que en todo caso permitiría diferenciar aspectos conceptuales diversos que aparecen juntos en una misma medida real (no obstante, creo que hay muchos casos de medidas promocionales reales que sí encajan en una y solo en una de mis categorías, y en la medida en que así sea el esquema gana en utilidad). Veamos ya esas cuatro categorías.

\section{El premio puro}

Llamaré «premios puros» (o premios en sentido estricto) a las medidas o técnicas promocionales que cumplen exclusivamente una función retributiva, de premio y «reconocimiento»o elogio de ciertas conductas o trayectorias vitales especialmente virtuosas, meritorias o supererogatorias. Me refiero a las medallas, títulos, condecoraciones, etc. Las medidas de este tipo, aunque pueden conllevar (o incluso consistir exclusivamente en) un beneficio material o económico para el premiado, no cumplen la función de motivar la conducta.

Podría objetarse, obviamente, que la concesión de premios puede de hecho incentivar alguna pauta de conducta, pues la perspectiva del premio puede mover a la acción, y el premio ya concedido puede servir como ejemplo a terceros para motivarles a realizar conductas parecidas. Ante esto, hay que precisar lo siguiente: 1) Acabo de decir que el criterio que aquí sigo para hablar de función (en este caso, «no motivadora») es el de la finalidad perseguida por (aquí) quien concede el premio, y no la función (tal vez motivadora) que de hecho pueda cumplir en los potenciales beneficiarios: éstos puede que usen, o puede que no, el premio como incentivo para su conducta, pero en todo caso esta categoría del premio «puro» se define estipulativamente por el hecho de que quien lo da no busca motivar conductas (si así fuera, estaríamos ante el segundo concepto, el de «promesa de premio»). 2) En consecuencia, el caso extremo o «tipo ideal» de premio puro sería el que se concede ex post, y ni siquiera se ofrece o promete antes de ser realizada la conducta. Un premio, por así decir, mantenido «en secreto» por quien lo va a conceder, de modo tal que el potencial premiado no pudiera imaginar que lo obtendría si obrara de cierto modo, pondría claramente de

vistas y objetivistas sobre la interpretación; cuando hablo de la finalidad social del legislador, quien lo desee puede tomarlo perfectamente como «la finalidad de la medida» promocional (con ello nada cambia en mi análisis, y para mí no es momento éste de entrar en eso). 
manifiesto que la intención del dador del premio no podía haber sido la de motivar conductas. De todos modos, no es necesario exigir, para hablar de «premio puro», el que no se haga pública su existencia: cabe perfectamente pensar en un premio que, siendo pública la posibilidad de su concesión, tenga no obstante una finalidad -para el dador, que es lo que cuenta- exclusivamente «de premio» a una conducta ya realizada y en absoluto de incitación para que se realice (la publicidad puede obedecer a otros motivos) ${ }^{3}$. Por otra parte, la concesión misma de un premio, aunque antes no se hubiera publicitado su posibilidad (indicativo determinante de que el dador no podía querer motivar la conducta de quien lo obtuvo ni de quienes podían haberlo obtenido si hubieran actuado así), podría no obstante ser susceptible de tener una intención motivadora respecto de otros sujetos en el futuro (como ejemplo de lo que podrían conseguir). El caso extremo de premio puro sería entonces el de aquel que, además de no haber sido ofrecido ni publicado de antemano, se hubiera concedido por haber realizado una conducta especialmente única y extraordinaria que ya nadie puede volver a realizar (ni siquiera serían posibles conductas del mismo o similar tipo), de modo que nadie podría ser motivado en el futuro y no se puede ni siquiera sospechar que el dador tuviera esa intención de ulterior motivación. En suma, sería un premio creado (o al menos publicitado) ad hoc y ex post, por conductas irrepetibles.

Desde luego, no resulta nada fácil encontrar ejemplos de casos «extremos» de premios puros. Ni falta que hace. Entiéndaseme bien: ese «caso extremo» es un «tipo ideal» quizá imposible de encontrar en la realidad (al menos, en el Derecho); pero mi intención al comenzar poniendo el listón tan alto era simplemente enfatizar -exagerar-ad liminem, con fines heurísticos, los rasgos conceptuales de esta categoría. A fin de cuentas, la clave es la intención retributiva y no motivadora del dador, y esto puede de hecho cumplirse plenamente en muchos casos reales aunque hubiera sido posible una intención motivadora (mi extremo consistía en hacerla incluso imposible). No hay por tanto que ceñirse a ejemplos demasiado extraordinarios (se crea un premio para Champollion por haber descifrado la piedra Rosetta, para

\footnotetext{
${ }^{3}$ Hablando de publicidad, parece que las cosas se invierten si nos referimos a la concesión misma (no a la posibilidad) del premio: típicamente, el premio puro cumple su función de elogio, de reconocimiento (social), precisamente dando la máxima publicidad a su concesión (que suele hacerse en solemnes ceremonias públicas con mayor difusión cuanto mayor es la entidad del premio). Pero no habría que excluir del premio puro el que se concediera «en privado». Simplemente, el reconocimiento sería de mucha menor intensidad, por parte de una o pocas personas: se trataría de un premio de menor entidad. En todo caso, la publicidad de la concesión ha de tener la finalidad de aumentar la entidad del premio, y quizá la de «mostrar» a terceros un modelo valioso (cfr. infra), pero no la de incentivar la conducta de éstos.
} 
Amundsen por llegar el primero al Polo Sur, para Suárez por su labor en la transición democrática española; el nombramiento de «padre de la patria» a un golpista fundador de un nuevo régimen político es ad hoc, ex post, y desde luego ya no se quiere que esa conducta se repita...) ni demasiado «de laboratorio» (el mismo día de la abolición del servicio militar obligatorio se crea un nuevo premio para quien lo haya prestado del modo más disciplinado). Algunos premios existentes (condecoraciones civiles o militares, doctorados honoris causa, nombramientos de hijo predilecto, premios al negocio familiar que haya cumplido 150 años, etc.) se aproximan, en mayor o menor medida, al caso extremo de premio puro y caen básicamente dentro de esta categoría. Dicho esto hay que añadir que, por supuesto, seguramente la mayoría de los que solemos llamar «premios» buscan también una función motivadora y corresponden a mi categoría de «promesa de premio».

El premio puro no pretende motivar la conducta porque ésta consiste en una acción o sucesión de acciones (una «trayectoria») tan meritoria, heroica o virtuosa que quien concede el premio (máxime tratándose del Estado) no aspira a tanto como a incentivar su realización: no es función del Derecho moderno fabricar héroes ni hacer de los ciudadanos seres especialmente virtuosos. Pero, aunque no busque incentivarlas, si alguien llega a realizar esas conductas supererogatorias el Derecho no permanece indiferente: son conductas valiosas (según los valores del Derecho) que merecen un premio, y el Estado desea reconocerlas. Yo creo que ahí radica la explicación de por qué he preferido mantener a los premios puros dentro de la función «promocional» del Derecho: no promueven (no motivan) conductas, pero, al premiarlas y reconocerlas, sí promocionan ciertos valores y virtudes cívicas (y, por qué no, también ciertos fines utilitarios beneficiosos para una persona o para el conjunto de la sociedad) que el Estado considera dignos de un favorecimiento (aunque la técnica empleada sea más débil que la de la incentivación). La prueba de que esos valores o virtudes (que subyacen a y se manifiestan en las conductas) sí se ven promocionados o de algún modo favorecidos es mostrar que estos premios puros no se conceden sin más ante cualquier conducta meritoria, extraordinaria, que denote un sacrificio, entrega, destreza, aptitud, logro, etc. fuera de lo normal. Ha de tratarse de un mérito, aptitud, logro, etc. que el Derecho considera valioso, porque expresa ciertos valores (no cualesquiera) o contribuye a ciertos bienes asumidos como positivos por el Derecho. El Derecho no premia el mérito que supone escribir El Quijote en una caja de cerillas, ni muchas de las «heroicidades» jurídicamente irrelevantes que merecen en cambio un lugar preeminente en el Libro Guinness de los Récords. El Derecho premia (sin incentivar) según qué conductas porque desea ensalzar y hacer avanzar según qué valores. El premio puro no se vincula tanto a la dimensión regulativa del 
Derecho cuanto a su dimensión valorativa, respecto de la cual también versa la «función promocional».

Precisando aún más: podría decirse que el Estado valora esas conductas, pero que, al menos en muchos casos, las conductas valoradas son aquellas que se han realizado precisamente no en atención a (movido por el interés en) la obtención del premio, sino por otras razones más encomiables (que manifiestan virtudes de altruismo, solidaridad, esfuerzo, valentía, abnegación y competencia en el trabajo, pericia y entrega en terrenos como la ciencia, el arte, el deporte...). Ahí radica el mérito, la cualidad intrínseca de la conducta, que se desea premiar. Por eso he hablado de una función «retributiva», en un sentido al menos próximo al de Kant. La función del premio puro no es la de prometérselo a alguien para motivarlo a que realice la conducta (cuya simétrica, entre las funciones de las sanciones negativas, sería la prevención especial), y ni siquiera la de que su concesión ya otorgada sirva de ejemplo para motivar a terceros en el futuro (cuya simétrica, en las sanciones negativas, sería la prevención general), sino simplemente la de otorgarlo porque la conducta lo merece en sí misma. Creo que la pena o sanción negativa no puede ser lo simétrico al premio puro porque la pena no puede prescindir de su función social preventiva; sin embargo, creo que sí tendría sentido hablar de premios con una exclusiva función retributiva (positiva) y en absoluto motivadora. Si el agente actuó movido (principalmente) por el premio, la función de éste (en cuanto que premio puro) quedaría desvirtuada. Si alguien realiza un acto externamente conforme $a$ un modelo heroico de conducta durante una batalla, pero lo hizo para ganarse una medalla, no tendría sentido, en puridad, concedérsela: lo que la medalla premia y reconoce es el heroísmo (no simplemente el acto externo), y éste habría desaparecido si la intención del soldado era su puro interés personal en obtener la medalla. Del mismo modo que tampoco tendría sentido la medalla si realizó ese mismo acto por simple error, o porque se había vuelto loco ${ }^{4}$.

\footnotetext{
${ }^{4}$ De modo similar podría decirse que la canonización como santo se negaría a aquel que ha seguido externamente un modelo de vida santa pero con la sola intención de ser canonizado como santo. En esto, la canonización sería un buen ejemplo de premio puro. Pero tengo serias dudas sobre si la institución de la santidad no tiene también funciones (intenciones) motivadoras para la Iglesia Católica, pues parece que la canonización como santo persigue incentivar ese modelo de conducta. Este ejemplo sería adecuado si uno distingue entre la santidad (las «vidas de santos") como modelo de vida que se propone a los fieles, y la institución de la canonización de santos como premio: si ese «premio» no persiguiera motivar vidas santas (que aún así se proponen), sino que se concede exclusivamente a quien ha llevado una vida santa sin que su motivo fuera ser canonizado como santo, creo que el ejemplo funcionaría. Doctores tiene la Iglesia a quienes preguntarles si las cosas son efectivamente así. Por mi parte, sólo añadiré que otro ejemplo de premio tomado de la religión, el cielo, quizá correspondería a mi ca-
} 
Me temo que, por más que me esfuerce, este concepto de «premio puro» no dejará de parecer un tanto extraño. Confieso que yo mismo me siento incómodo al intentar caracterizarlo como lo estoy haciendo. Pero sospecho que esta incomodidad resulta inevitable para cualquiera que hable de premios, porque en su raíz se encuentra una dificultad más de fondo: la de hacer encajar una institución premoderna, como es la promoción de virtudes, en el seno del Derecho de impronta «liberal» contemporáneo. Se me ha objetado, por ejemplo, que probablemente sea cierto que el premio puro no persigue motivar la conducta del individuo concreto al que se premia (no cumpliría una finalidad simétrica a la de la «prevención especial» de las sanciones negativas), pero que en todo caso sí busca motivar la conducta de terceros, la de la sociedad ante cuyos ojos se presenta al premiado como un modelo a seguir (simétricamente a la prevención general); de lo contrario, no se ve qué papel social pueda jugar el premio (y el premio, al menos el otorgado por el Derecho, no puede dejar de estar socialmente orientado). En suma, el premio puro no incentivaría conductas concretas del premiado (se reconoce que el Estado «no quiere hacer héroes») pero sí «modelos de vida» que no dejan de ser también de conducta (aunque se trate de modelos globales de conductas indeterminadas que desean motivarse en un auditorio difuso). Ante esto he de decir de entrada que, si se aceptan las razones que explican que la concreta conducta del premiado sólo se desee reconocer y no motivar (razones del tipo «el Derecho no busca hacer héroes», ni incentivar conductas virtuosas), ¿por qué entonces sí iba el Derecho a querer motivar las conductas virtuosas de terceros? Las mismas razones que valen para (no querer motivar) la conducta del premiado valdrán, a fortiori, para (no querer motivar a) la sociedad en general. Queda, por supuesto, la cuestión de cuál será entonces la relevancia social del premio puro. Aparte de la obvia relevancia que ya tiene sobre los individuos concretos a los que se premia, la respuesta en realidad ya ha sido apuntada, cuando hice referencia al reconocimiento social y a la promoción general (social) de ciertos valores y virtudes cívicas, que reciben un trato de favor frente a otros, aunque no se motiven (ni motivación especial ni motivación general) conductas. Alguien podría decir incluso que el premio puro no opera en realidad sobre conductas. Yo diría mejor que sí opera sobre conductas, pero de un modo distinto al del incentivo motivador: opera sobre conductas pero solamente en cuanto que éstas son el «soporte material» de virtudes, de «disposiciones de carácter», cualidades o méritos; no es la conducta externa lo que se reconoce

tegoría de premio puro si se tomara -por el dador- como se toma en el conocido poema (atribuido, entre otros, a Teresa de Ávila) «No me mueve mi Dios para quererte... (el cielo que me tienes prometido)». Pero me parece que Santa Teresa es, en este poema, más kantiana que católica. 
(y menos aún se motiva), sino la virtud intrínseca que la conducta concreta ejemplifica incorporándola en su «aspecto interno». Además de reconocerla, ¿también se quiere «motivar» esa virtud? La respuesta no es fácil, y depende de cuán «liberal» queramos ver al Derecho contemporáneo. Los premios remiten a las virtudes, y ello chirría al subsistir en un Estado liberal moderno sólo preocupado por conductas (especialmente por reprimir las indeseables siguiendo el criterio del daño) y que quiere ser neutral acerca de virtudes, disposiciones de carácter, modelos excelsos de vida, o ideales de perfección humana (no por casualidad el renacer del Derecho premial vino de la mano del Estado social, con sus tendencias «perfeccionistas» para el gusto liberal) $)^{5}$. Yo me inclino a pensar (no estoy muy seguro) que el Derecho moderno -nos guste o no- ni siquiera se propone motivar «virtudes internas» en este sentido. Su rastro premoderno se limitaría a elogiar esas virtudes («reconocerlas» en las personas en que se den y en -a través de- las conductas en que se manifiesten), y a «mostrarlas» como valiosas ante la sociedad, y ambas tareas son desempeñadas por los premios puros. Tendrían algo así como una función simbólica, ideológica, educativa. Se puede decir incluso que el derecho moderno no es neutral sino que «quiere» que desarrollemos esas virtudes (y que se realicen las conductas concretas que las encarnan); pero no llega a querer suministrarnos motivos para ello. Desde luego, no quiere dar motivos para realizar las concretas conductas virtuosas. Quizá la solución (la explicación de lo que defiendo) radique en distinguir entre guiar la conducta (decirnos qué hacer) y motivarla (dar razones o in-

\footnotetext{
${ }^{5}$ «Que premios e incentivos hayan perdido sus específicas fisonomías por el hecho de que ambos han sido investidos por un proceso de legislación masivo y, parece, irreversible, es un dato de hecho. Sostengo que esto es sólo un efecto. La causa, que aquí sólo puedo mencionar, radica en mi opinión en un hecho cultural de gran alcance: me refiero al declive, y quizá a la desaparición, de las doctrinas de la virtud. Las teorías de la virtud (en sus diversas formulaciones, de las clásicas como hábito o disposición a las más modernas de virtud como esfuerzo) establecían una conexión muy estrecha entre la virtud y sus obras. La premialidad podía ser considerada como un reconocimiento de la virtud e, indirectamente, una incitación a realizar acciones virtuosas. El premio se dirigía no a la acción buena, sino al hombre bueno. La premialidad desaparece del Derecho, quizá no por casualidad, precisamente cuando el Derecho se ocupó cada vez menos de disposiciones y cada vez más de acciones. Si este cambio ha sido un progreso o bien un regreso de la cultura jurídica, es cuestión importante y harto compleja, sobre la que no quiero tomar partido. Queda como un hecho que la técnica del incentivo es perfectamente coherente con la idea de que el Derecho se interesa sólo, o casi sólo, por las acciones, por los resultados, en una palabra, por las obras. Mientras tanto, también la vieja premialidad vuelve al escenario del Derecho, pero se encuentra con un socio, el incentivo, que tiene y persigue intereses bien distintos. Y no resulta fácil ver cómo pueda disolverse una sociedad hecha así, ciertamente ambigua, pero, parece, también lucrativa» (Giacomo Gavazzi, «Diritto premiale e diritto promozionale», en VV.AA., Diritto premiale e sistema penale, Giuffrè, Milano, 1983, pp. 37-52, en p. 52, cursiva mía).
} 
centivos para hacerlo). A través de los premios puros, al elogiar la virtud del premiado, el Derecho también está proporcionándonos indirectamente una guía de conducta, señalándonos una pauta o modelo de conducta a seguir; pero no llega a querer darnos ningún motivo, ningún incentivo, para seguirlo: es una guía sin sanción (positiva). La analogía, como ya apunté, es la de las «vidas de santos», no la del cielo ni la canonización como motivo para seguir una vida santa. La guía es sólo indirecta (implícita) porque el premio puro es primariamente reconocimiento, juicio de valor (dije que se vincula más a la dimensión valorativa que a la regulativa del Derecho), pero todo juicio de valor implícitamente incorpora (compromete a) un aspecto regulativo (Hare). En todo caso, el premio puro indirectamente nos dice: «haced esto» (o mejor: «sed así», sed de tal modo que hagáis conductas como ésta). Pero no llega a decirnos: «para que hagáis esto, para que tengáis un motivo para hacerlo, os ofrezco un premio». No se puede incentivar una conducta sin a la vez guiarla, pero sí se puede, viceversa, guiar en la sociedad una conducta (mostrar indirectamente qué hacer) sin aportar incentivos para seguirla, y creo que esto es lo que ocurre con los premios puros. Por otra parte, si se acepta mi anterior discurso «kantiano» acerca de que el premio lo que reconoce es la intención meritoria (y no la simple conducta externa motivada por error, locura, o el interés en ganar el premio), entonces se entenderá que es un sinsentido decir que el premio puro quiere motivarnos para que actuemos no movidos por él (darnos un motivo para que obremos sin usarlo como motivo es no darnos un motivo).

\section{La promesa de premio}

Llamaré «promesas de premio» (también podemos llamarlas «premiosincentivo») a las medidas o técnicas promocionales que cumplen simultáneamente, por un lado, una función retributiva (de premio y «reconocimiento» o elogio de ciertas conductas meritorias consideradas valiosas por el Derecho), y, por otro lado, una función «motivadora» (de incentivo de la conducta, suministrando «razones para la acción» respecto de esas mismas conductas). Las promesas de premio incentivan la conducta ex ante, y la reconocen ex post (además de incentivarla en terceros para el futuro).

En esta categoría entraría la mayoría de las medidas que solemos denominar «premios», porque conllevan la idea de elogio a la conducta que se hace merecedora de ellos, y su ofrecimiento -como suele ser lo común- se publicita, y se publicita con la intención de incentivar esa conducta, la cual se quiere incentivar precisamente por la vía de prometer un beneficio a quien la realice. Por ejemplo, las convocatorias de premios para quien realice la mejor obra científica, artística o literaria de un determinado tipo que se quiere promover (más claramente aún si se exige que la obra sea inédita); o la ins- 
titución de la «Matrícula de Honor» (con o sin exención de tasas para el curso siguiente) para premiar al buen estudiante y a la vez motivar a todos para que estudien; o los premios, ofrecidos primero y luego concedidos con todos los honores, a aquellos agricultores cuyas cosechas alcancen un determinado nivel en un producto preferente para un plan quinquenal del Gobierno; o las promesas de promoción en el puesto de trabajo o de complementos salariales a quienes destaquen en la realización de ciertas tareas (como los «sexenios de investigación» en la universidad española).

En estas promesas de premio suele ofrecerse algún beneficio económico o material, pero siempre existe a la vez un aspecto de reconocimiento al autor de un acto u obra meritoria, lo cual las distingue de los puros incentivos (que motivan pero no reconocen, como veremos a continuación). Y, en sentido inverso, aunque a veces el beneficio prometido puede consistir en el simple reconocimiento, seguimos estando en esta categoría si ese reconocimiento se ofrece con la intención de que sirva de incentivo para motivar la conducta 6 . Lo cual distingue esta vez a las «promesas de premio» de los «premios puros» (que reconocen pero no motivan, como ya vimos).

Nada hay por tanto de incoherente aquí (a diferencia de lo que vimos que ocurriría en los premios puros) cuando se premia a alguien que actuó con la intención precisamente de obtener el premio. Ello no «desvirtúa» en absoluto al «premio-incentivo». Al contrario: para eso -para que actuara movido por él- era para lo que se había ofrecido. Y la dimensión de «reconocimiento», que sigue existiendo en esta «promesa de premio», no por ello desaparece: se considera que hay razones que justifican elogiar la conducta aún cuando su móvil fuera el premio (cosa, por cierto, que no necesariamente ha de ocurrir de hecho, aunque ésa sea la intención de quien promete el premio). Obviamente, no será ese móvil «interesado» de obtener el premio lo que justifique su componente de reconocimiento. Ha de haber elementos adicionales en la conducta (que pueden tener que ver con intenciones concomitantes y/o con aptitudes o méritos «objetivos», distintos de la intención subjetiva) que justifiquen su carácter meritorio: la conducta sigue poniendo de manifiesto virtudes valiosas para el Derecho del tipo de las que ya vimos al referirnos a los premios puros (pericia, esfuerzo, solidaridad, valentía, etc.), y son esas virtudes (no la intención de obtener el premio) las que, ex post, son objeto de «reconocimiento». Por supuesto, la exis-

\footnotetext{
${ }^{6}$....además de con la intención genuina de reconocer, se entiende. Si esa simultánea intención de reconocer por parte del dador en realidad no existe, sino que el supuesto reconocimiento es sólo un instrumento de motivación, nos encontraríamos ante un incentivo puro (cfr. infra) disfrazado de reconocimiento. Creo que un ejemplo de esto podría ser la institución del «empleado del mes» en los restaurantes McDonald's norteamericanos...
} 
tencia (en su caso) del móvil (buscado por el dador) de obtener el premio (esa razón prudencial, no «por deber», aunque coexista con razones genuinamente morales) hace que la conducta sea significativamente menos «virtuosa», heroica, meritoria o supererogatoria que la que cualificaba para un «premio puro». Pero no por ello la conducta deja de ser digna de un cierto reconocimiento.

Por otro lado, el que no sea una conducta tan heroica explica que el dador (también si es el Estado) sí aspire esta vez a motivarla, y no sólo a reconocerla (a diferencia de lo que ocurría en los premios puros). Y ello a pesar de que dicha conducta no constituía un deber para el destinatario. Esto último es lo normal en estos «premios-incentivo», pero no es un requisito necesario: cabe pensar en casos extraordinarios (o quizá no tanto) en los que se promete un premio para incentivar y reconocer una conducta consistente en el correcto cumplimiento de un deber jurídico del destinatario. Por ejemplo, para combatir el absentismo laboral, se prometen beneficios y honores -en lugar o además de amenazar con sanciones negativas- a quien efectivamente cumpla con la jornada y calendario laboral que tiene el deber de cumplir. Se prestan más aún a estas medidas los deberes que no son de cumplimiento pleno de una conducta concreta, sino que son deberes de maximización de un estado de cosas dejando discrecionalidad en cuanto a la conducta idónea para ello.

Esta categoría de las promesas de premio corresponde a las medidas que han de considerarse sanciones jurídicas positivas propiamente dichas. Las cosas encajan: la denominación de «sanciones» positivas se justifica sólo en el caso de las promesas de premio, porque sólo aquí se puede trazar una simetría funcional con las sanciones negativas. La sanción negativa es la promesa (amenaza) de un mal y cumple tanto una función retributiva (negativa) ex post -se castiga porque la conducta en sí misma lo merece- como motivadora (preventiva) ex ante, para disuadir, para incentivar la omisión de conductas indeseables. Esta segunda función se cumple al amenazar, y también al imponer efectivamente la sanción (la imposición sirve de ejemplo a terceros, que ven la eficacia del castigo que recibirían también ellos). La promesa de premio como sanción positiva es, simétricamente, la promesa de un bien y cumple tanto una función retributiva (positiva) ex post -se premia porque la conducta en sí misma lo merece- como motivadora (incentivadora) ex ante, para incentivar la realización de conductas deseables. Esta segunda función se cumple al prometer, y también al conceder efectivamente el premio (la concesión sirve de ejemplo a terceros, que ven el premio que recibirían también ellos). Ya expliqué por qué esta simetría no existe en el caso de los premios puros (en ellos falta la función incentivadora, simétrica de la preventiva, la cual no puede faltar en la pena). En los casos 
que nos faltan por ver tampoco existe esta simetría: los incentivos puros carecen de la función retributiva (tampoco ésta, en mi opinión, puede faltar en la pena), y las facilitaciones carecen de ambas funciones.

\section{Los incentivos puros}

Llamaré «incentivos puros» (o «incentivos en sentido estricto») a las medidas o técnicas promocionales que cumplen exclusivamente una función «motivadora», de guía e incentivo, suministrando «razones operativas para la acción» respecto de ciertas conductas.

Los incentivos puros únicamente buscan motivar $e x$ ante, pues, una vez realizada la conducta, la concesión del incentivo prometido no representa «reconocimiento», premio o elogio alguno por méritos o virtudes encomiables, sino simplemente el cumplimiento del deber al que se había comprometido quien ofreció el incentivo.

Nada impide que ese cumplimiento, el «libramiento» del beneficio, se realice sin publicidad (no se busca un reconocimiento social), aunque el ofrecimiento del incentivo sí necesita obviamente ser publicitado entre los potenciales destinatarios para que se puedan sentir motivados por él.

La conducta incentivada suele ser, típicamente, una actividad económica o empresarial, cuya realización se desea favorecer creando o incrementando el interés particular del destinatario en realizarla, por su propio provecho; aunque, si el dador (tratándose del Estado) la incentiva, es porque objetivamente ello redunda en beneficio de (promociona) un fin público o general, normalmente un objetivo socioeconómico o policy que se desea promocionar. El beneficio con que se incentiva suele ser también de tipo económico o material; en todo caso, es difícil imaginar que ese beneficio pudiera ser de tipo honorífico sin que ello incorporara al incentivo puro la dimensión de reconocimiento de la que debe carecer (pero cfr. supra, nota 6).

Lo importante es que la conducta del destinatario no es considerada por el dador especialmente digna de elogio (ningún mérito o virtud se elogia en los agricultores cuando se les subvenciona para que arranquen las viñas); o al menos, aunque de hecho sea meritoria, no es intención del dador emplear el incentivo como medio de reconocimiento de ese mérito. El incentivo puro sólo cumple funciones motivadoras ex ante, en absoluto retributivas ex post. Por eso no hay aquí simetría con la sanción negativa: ésta no puede prescindir de su dimensión de reproche y de castigo sólo imponible a quien lo merece, con culpabilidad; mientras que en el incentivo puro no existe un simétrico elogio ni se requiere mérito alguno, sino que basta con la realización de la conducta externa o conforme. El otorgamiento ex post del incen- 
tivo comprometido, si acaso, cumple únicamente, a su vez, ulteriores funciones motivadoras ex ante, en cuanto ejemplo que pueda servir de incentivo a terceros en el futuro.

Más aún: síntoma de que en el incentivo puro no existe el elemento de premio o «reconocimiento» ex post por conductas ya realizadas es el hecho de que, en muchas ocasiones (aunque esto no es requisito para hablar de incentivo puro), el beneficio en que consiste el incentivo se entrega con anterioridad a la realización misma de la conducta: nada puede haber de premio (de reconocimiento) en algo que se otorga por una conducta aún no realizada. Ejemplos de incentivos puros son las subvenciones a determinadas actividades económicas realizadas con ánimo de lucro; las ayudas y créditos blandos que se otorgan de antemano a los empresarios; muchos tipos de desgravaciones y beneficios fiscales...

Es cierto que muchos incentivos se ofrecen no a cualquiera sino únicamente a quienes reúnan ciertas capacidades o cualificaciones y/o hayan realizado cierto tipo de conductas en el pasado, y que ello podría interpretarse como una especie de premio o reconocimiento de méritos. Mi respuesta ante esto es la siguiente. a) Si efectivamente ocurre eso, simplemente habremos dejado de estar en la categoría del incentivo puro, y nos encontraremos ante una peculiar combinación de premio e incentivo: se trataría de un premio (sea «puro» 0 «promesa de») cuya peculiaridad radicaría en que el beneficio otorgado como reconocimiento consistiría no en una medalla, sino en haber sido elegido como destinatario de un incentivo para realizar una ulterior conducta (ejemplo: concesión de una prestigiosa beca o año sabático a un gran académico, en atención a sus méritos, para investigar en el extranjero); dicho incentivo puede a su vez ser un incentivo puro o ser una promesa de premio (en el caso de que exista, además, un elogio a la segunda conducta una vez realizada). b) Me parece que, normalmente, no es eso lo que ocurre en estos casos, los cuales suelen seguir siendo incentivos puros. La restricción de un cierto «historial previo» como requisito para ser destinatario de un incentivo no suele operar como un «reconocimiento» a dicho historial, sino como una simple forma de seleccionar (por razones técnicas y de economía, para maximizar la utilidad del incentivo) qué destinatarios son de hecho más idóneos para ofrecerles el incentivo por encontrarse en mejor situación o capacidad de realizar con éxito la conducta que se desea incentivar, sin que al dador le interese en absoluto elogiar los méritos de quien haya alcanzado dicha capacidad. Sea como fuere, no hay que perder de vista que, según el criterio que yo he propuesto, la intención relevante para decir si nos encontramos en a) o en b) es la intención del dador, y no el cómo se lo tome el destinatario. 


\section{Las facilitaciones}

Llamaré «facilitaciones» a las medidas o técnicas promocionales cuya función consiste exclusivamente en facilitar (proveer) los medios para: 1) o bien posibilitar al destinatario la realización de ciertas conductas que de otro modo le resultaría empíricamente imposible realizar; 2) o bien facilitar o hacer «razonablemente posibles» determinadas conductas que de otro modo, aunque empíricamente posibles, le resultarían tan difíciles y gravosas que realizarlas supondría un acto supererogatorio que ni se pretende ni sería razonable esperar que llevara a cabo; 3) o bien, en algunos casos, simplemente hacer algo más fácil una conducta que de otro modo resultaría más gravosa (pero ni estrictamente imposible, ni tampoco especialmente heroica) ${ }^{7}$.

\footnotetext{
${ }^{7}$ Cabría añadir entre las «facilitaciones» a aquellas medidas cuya finalidad es posibilitar o facilitar al destinatario la realización de ciertas conductas que, de otro modo, no es que sería imposible o gravoso realizarlas empíricamente, sino que: o bien a) no serían jurídicamente posibles (y la conducta, como tal conducta en sí misma jurídica, sería imposible sin más); o bien b) no estarían jurídicamente permitidas.

a) El primer tipo de estas, digamos, «facilitaciones jurídicas» consistiría en medidas dirigidas a posibilitar, mediante reglas que confieren poderes, conductas jurídicas (la realización de actos jurídicos, como contratos, testamentos, etc.) que de otro modo no sería posible realizar, porque dichas reglas «constituyen» la posibilidad misma de producir esos resultados «institucionales». No me ocuparé aquí de este sentido de «facilitación» porque hacerlo supondría entrar en un terreno que nos llevaría muy lejos respecto de la función promocional del Derecho de la que venimos hablando (referida a conductas físicas, no jurídicas). Pero conviene al menos apuntar que la finalidad de las reglas que confieren poderes viene a coincidir con la de las facilitaciones de conductas físicas de las que me ocupo aquí: al igual que, como en seguida veremos, ocurre en mis «facilitaciones», las reglas que confieren poderes no suministran al destinatario razones operativas para producir el resultado jurídico; únicamente constituyen la posibilidad del mismo. Como mucho, las reglas que confieren poderes, al igual que las «facilitaciones» de conductas físicas, aportarían simplemente razones auxiliares: unas y otras, todo lo más, participan de un modo indirecto (y normalmente más débil) en la guía de la conducta, ya que necesitan ser completadas con alguna razón adicional genuinamente operativa que motive la conducta. (Cfr. Atienza, Manuel, y Ruiz Manero, Juan, Las piezas del Derecho, Ariel, Barcelona, 1996, esp. pp. 66-73).

b) En cuanto a las «facilitaciones jurídicas» del segundo tipo, el «objeto facilitado» seguiría siendo una conducta física (sólo que la facilitación de la misma consistiría en permitir -lo cual es distinto de posibilitar- jurídicamente su realización, levantando una prohibición), por lo cual no habría dificultad alguna para entenderlas incluidas en mi concepto de facilitación. Estas facilitaciones podrían entenderse subsumidas en los casos 2) y 3) de mi definición, pues el «sacrificio no razonablemente esperable», o la «simple carga», respectivamente, que la facilitación viene a suprimir, bien pudiera consistir en una prohibición (o quizá en algún otro tipo de gravamen jurídico) que dificultaba la conducta empíricamente realizable. De todos modos, tampoco es en este segundo tipo de «facilitaciones jurídicas» en el que estoy típicamente pensando al elaborar este concepto de facilitación (lo que tengo en mente es más bien la aportación de medios materiales para posibilitar o facilitar empíricamente la conducta).
} 
Lo importante es que las facilitaciones no pretenden -ni siquiera en el caso 3)- otorgar un «beneficio» o un «bien» de una entidad suficiente como para que éste opere en el razonamiento del destinatario como una razón o estímulo para realizar la conducta (como ocurría en los incentivos y en las promesas de premio), y mucho menos presentan algún aspecto de reconocimiento, premio o elogio de méritos (como ocurría en los premios puros y en las promesas de premio). Las facilitaciones simplemente intentan proporcionar al destinatario los medios necesarios (podríamos decir, la infraestructura) para hacer posible o menos gravosa la conducta. Pero contar con los medios para hacer algo - que nos sea posible, y además no especialmente costoso, realizarlo- no es todavía razón suficiente para hacerlo. El destinatario necesitará, además, alguna razón adicional, «en positivo», para actuar: no simplemente saber que, si quiere, puede; necesitará alguna razón para querer hacerlo. La facilitación no intenta proporcionar esa razón (si lo hiciera, nos habríamos pasado a la categoría del incentivo o a la de la promesa de premio). En suma, la facilitación, ni intenta «reconocer» conductas meritorias, ni intenta «motivar» la realización de conducta alguna: no estimula la conducta, no da «razones para la acción». O mejor dicho, por usar los conceptos de Raz, la facilitación no da «razones operativas» para la acción, sino que simplemente proporciona «razones auxiliares» (o modifica favorablemente el cuadro preexistente de razones auxiliares), por sí solas insuficientes para mover a la acción.

Son facilitaciones, por ejemplo, muchas de las medidas promocionales que adopta el Estado respecto de los discapacitados físicos. Algunas de ellas suponen posibilitar acciones de otro modo empíricamente imposibles. Por ejemplo, si los ejercicios de unas oposiciones son escritos, preparar una versión Braille de las preguntas para los invidentes; o si son orales, permitir a los mudos contestar por escrito (ésta en realidad sería una facilitación jurídica, cfr. supra, nota 7, b). El Estado no tiene un interés especial en que sean ciegos o mudos quienes se presenten a esas oposiciones, ni tampoco en incentivar a ciegos y mudos para que accedan a ese concreto puesto de trabajo. Simplemente, desea remover la imposibilidad a la que se enfrentaría aquel ciego o mudo que deseara ese puesto, pero esta medida ni da ni pretende dar a ese sujeto motivo alguno en positivo para concurrir a esa oposición. Otras veces, tal vez la mayoría, las medidas para los discapacitados pretenden lograr que sea para ellos «razonablemente posible» cierta conducta que de otro modo sería quizá empíricamente posible, pero tan gravosa que, en la práctica, su dificultad vendría a equivaler a su imposibilidad. Circular libremente por las calles de una ciudad donde no se han suprimido las barreras arquitectónicas puede que no sea literalmente imposible para quien está en una silla de ruedas porque en abstracto existen medios para superar esa 
dificultad. Pero pretender que sea el propio discapacitado quien provea dichos medios (contar siempre con alguien que le ayude, o pagar a alguien para ello, o sufragar él los costes de la construcción de rampas) significaría esperar de él -aunque tuviera la capacidad para aportar esos medios- un sacrificio tan exagerado que sería absurdo e injusto esperarlo. Algo parecido cabe decir de los aparcamientos reservados para automóviles de discapacitados. Lo interesante en estos ejemplos es mostrar que el Estado, al dar esas facilitaciones, no pretende motivar a los beneficiarios para que hagan uso de ellas y realicen las conductas, sino únicamente hacérselas posibles o más fáciles, para hacer efectiva la igualdad con los no discapacitados. Al Ayuntamiento le resulta indiferente que los discapacitados circulen de hecho más o menos por la ciudad con su silla de ruedas o con su automóvil. No es la conducta misma lo que se quiere fomentar, sino la igualdad que supone el que les sea posible. Es más, bien pudiera ser que el Ayuntamiento, para reducir la contaminación y el caos de tráfico, estuviera desarrollando políticas (incluyendo incentivos) para que los vecinos (discapacitados o no) dejaran el coche en casa, y aún así mantuviera aparcamientos reservados a minusválidos. Con ellos, ese Ayuntamiento no quiere incentivar a los discapacitados para que conduzcan (desea lo contrario), pero los mantiene en aras a la igualdad. En general, en este tipo de facilitaciones, el «fin general» a promocionar es la igualdad de oportunidades, y no el bien o fin que resultaría como consecuencia de la realización de las conductas. Por otra parte, al dar estas facilitaciones a los discapacitados, tampoco se está «reconociendo» ni elogiando un supuesto «mérito» consistente en «ser discapacitado» ni nada por el estilo: proporcionar sillas de ruedas, construir rampas, o reservar aparcamientos, no supone «premio» alguno merecido por alguna conducta o trayectoria vital valiosa.

Muchas veces, estas facilitaciones están vinculadas a cuestiones de coordinación de conductas. Un ejemplo típico es la provisión de contenedores de basuras adecuados para el reciclaje, separando los de vidrio, papel, etc. Sin ellos no sería «razonablemente posible» la conducta del ciudadano ecológicamente concienciado. Algún héroe del ecologismo podría, como cuestión empírica, clasificar su basura y distribuirla él mismo entre las diversas plantas de reciclaje fuera de la ciudad, pero eso nada quita a la idea de que sin contenedores del Ayuntamiento el reciclaje de basuras sería «imposible». Aquí es la coordinación de conductas en todo un colectivo, no la conducta individual (que sería insignificante), lo que entra en juego. Proveer los medios (contenedores) para el reciclaje posibilita las conductas de reciclaje de los ciudadanos, coordinándolas entre sí. Pero serán necesarios ulteriores incentivos, o confiar en los motivos que la gente pueda tener para reciclar, porque la simple disposición de contenedores en todas las calles nos posi- 
bilita contribuir al reciclaje, pero no nos da motivo alguno para ello. Y, sin embargo, que la conducta sea posible, ya supone en sí mismo un modo de promocionar un fin (el fin general, en este caso, sería la protección del medio ambiente), aunque no se incentive conducta alguna y esta técnica de promoción resulte por ello normalmente más débil.

\section{Cuadro-resumen}

Hasta aquí, mi construcción conceptual de las cuatro técnicas promocionales fundamentales. El siguiente cuadro sintetiza la clave de estas distinciones:

Técnicas promocionales

\begin{tabular}{|l|c|c|c|l|}
\hline $\begin{array}{l}\text { Técnica Finalidad } \\
\text { promocional }\end{array}$ & Reconocer & Motivar & $\begin{array}{c}\text { Posibilitar } \\
\text { o facilitar }\end{array}$ & \multicolumn{1}{|c|}{ Ejemplos } \\
\hline Premio puro & sí & no & no & Nombramiento de hijo predilecto \\
\hline Promesa de premio & sí & sí & no & Matrícula de honor \\
\hline Incentivo puro & no & sí & no & Créditos blandos a empresas \\
\hline Facilitación & no & no & sí & Aparcamientos para discapacitados \\
\hline
\end{tabular}

\section{Tres matizaciones}

Resta todavía realizar tres puntualizaciones:

1) La promesa de premio es una categoría mixta.- Hace tiempo que se habrá advertido que, conceptualmente, y en puridad, la «promesa de premio» no es una categoría independiente, sino mixta: es la categoría que surge de la suma, en una misma medida, del premio puro y del incentivo puro (la suma hace que uno y otro dejen de ser puros). Carece pues de rasgos adicionales, distintos de los que proceden del premio y del incentivo en sentido estricto. Por eso dije que las promesas de premio pueden denominarse también «premios-incentivo». Ya advertí al comienzo que, en la práctica, las cuatro técnicas promocionales pueden aparecer combinadas entre sí de diversos modos, y que, en la determinación de los «conceptos primarios» a partir de los cuales formar esas combinaciones, perfectamente podríamos (si se quiere, debíamos) haber prescindido de las promesas de premio. Si he decidido no obstante incluir a las promesas de premio entre los cuatro conceptos básicos, en el mismo nivel que los otros tres, ha sido simplemente porque me parece que esta específica combinación, más que ninguna otra de las posibles, tiene una importancia, una «fuerza promocional» (como enseguida veremos), y se da en la práctica con una frecuencia tal, que justifica formar con ella una categoría autónoma. Y sobre todo porque, como hemos visto, sólo fabricando este concepto combinado encontraremos, en el 
ámbito promocional o positivo, el concepto simétrico de la sanción negativa tradicional de los ordenamientos represivos. No me refiero a su analogía estructural con las sanciones negativas, sino a su analogía (o simetría) funcional: las tradicionales funciones retributiva-negativa (castigo) y preventiva (disuasoria) de la sanción negativa tienen su reflejo en las funciones retributiva-positiva (premio) y motivadora (incentivadora) de la «promesa de premio». Siendo pues el concepto clave, soy perfectamente consciente de que la «promesa de premio» no constituye, en el plano estrictamente conceptual, un concepto primario sino sólo una combinación de premio e incentivo.

2) La diversa «fuerza promocional».- Las promesas de premio son una técnica promocional mucho más «fuerte» (más capaz de lograr sus fines) que los premios puros, y más fuerte también que los incentivos puros y que las facilitaciones. En los premios puros se «favorecen» (promocionan) ciertas virtudes y valores sólo en el débil sentido de que éstos «se hacen avanzar» de algún modo simplemente porque premiarlos (reconocerlos) supone un cierto «trato de favor» simbólico o ideológico (se muestran como valiosos ante la ciudadanía) frente a otros valores o méritos que no reciben premio; pero no se pretende incentivar la conducta que no obstante se premia. Los incentivos puros son una técnica mucho más fuerte que los premios puros, porque dan razones para actuar; pero las promesas de premio añaden, a esa misma fuerza motivadora del incentivo puro, el plus promocional (por débil que sea) del «reconocimiento» que tenían los premios puros. Las facilitaciones son normalmente más débiles (en cuanto a su virtualidad promocional) que las promesas de premio y que los incentivos, porque no suministran razón alguna para actuar, sino que simplemente hacen posible o «razonablemente posible» la conducta, cosa que se sobreentiende que ya se daba en el caso de las conductas a las que se refieren los incentivos puros y las promesas de premio: se supone que si se incentiva una conducta (o si se incentiva y además se reconoce), es porque esa conducta ya era razonablemente posible. La facilitación aporta pues un elemento necesario pero no suficiente, y ese prerrequisito ya se daba en el incentivo y en la promesa de premio, los cuales aportan algo más. Dicha «posibilidad razonable» de realizar la conducta no se presupone siempre, sin embargo, en el caso de los premios puros. Es más: en ellos se trata normalmente de una conducta supererogatoria, y su carácter meritorio (a veces cuasiheroico) que es reconocido se debe precisamente a que no existía esa «posibilidad razonable». La facilitación aporta al menos dicha posibilidad razonable, y me parece que ello resulta promocionalmente mucho más útil que la función digamos ideológica del premio puro. Cierto es que la facilitación se detiene ahí, sin aportar razones operativas para realizar la conducta, pero en esa carencia el premio puro está a la par, porque tampoco busca motivar. En consecuencia, 
según su diversa «fuerza promocional» (de los fines generales a promocionar), podemos ordenar las cuatro técnicas de menor a mayor fuerza como sigue: premios puros, facilitaciones, incentivos, y promesas de premio. Por supuesto, esta ordenación parte de la conceptualización misma de cada técnica en abstracto: el contenido concreto que pueda darse a cada una puede trastocarnos este orden; por ejemplo, un incentivo puro de una cuantía económica enorme, aunque carezca del componente de reconocimiento, seguramente resultaría mucho más efectivo que una promesa de premio cuya cuantía económica fuera muy escasa (el plus del reconocimiento no compensaría ese desfase). A lo que me refiero, cuando establezco este orden, es a que, ceteris paribus, o bien si prescindimos de su contenido concreto, cada una de las técnicas promocionales tiene la capacidad promocional relativa indicada por esa ordenación.

3) Las compensaciones o indemnizaciones positivas.- Sería en mi opinión razonable plantearse al menos la posibilidad de añadir una quinta categoría: las medidas compensatorias o indemnizatorias, cuya finalidad es meramente resarcitoria, reparadora; es decir, las medidas que no consisten en ofrecer $u$ otorgar al destinatario un beneficio entendido como un plus añadido que mejore su situación, sino que solamente pretenden restituir el statu quo ex ante del destinatario que ha sufrido o pudiera sufrir un quebranto o sacrificio. La duda sobre si debemos añadir esta categoría puede surgir como consecuencia de reconocer su importancia en el terreno de las sanciones negativas: uno de los criterios tradicionales para distinguir entre sanciones penales y civiles es precisamente el de que la sanción civil es sólo resarcitoria (sólo se busca restituir al acreedor a su situación inicial, y se cumpliría su función si ello pudiera lograrse sin infligir un sufrimiento al deudor, por ejemplo si indemnizara un tercero); mientras que la sanción penal tiene una finalidad retributiva y preventiva (que en todo caso quedaría desvirtuada si no se infligiera un sufrimiento al autor mismo del ilícito). Quizá un análisis más refinado del que he podido realizar hasta aquí nos llevaría a una conclusión distinta, pero a falta del mismo creo que mi esquema perdería más que ganaría si incorporásemos las compensaciones como categoría autónoma.

A simple vista, alguien podría llegar a esta misma conclusión argumentando que las técnicas promocionales consisten en proporcionar (prometiéndolo o no) algún bien o beneficio (sea material o puramente honorífico) al destinatario, y que no se ve qué diferencia conceptual pueda suponer, a estos efectos, el que dicho bien o beneficio consista en mejorar su situación de partida o simplemente en compensar un perjuicio que su conducta (o algún otro suceso) pudiera ocasionarle y dejarle como estaba. A esto he de responder sin embargo que, efectivamente, igual da que el beneficio en que 
consiste la medida sea un beneficio neto o la compensación de una pérdida, pero que la cuestión no es ésa. La cuestión es para qué pueda darse ese beneficio, sea neto o resarcimiento: sólo para reconocer, para motivar y/o para posibilitar/facilitar, o bien si cabe darlo también para alguna otra finalidad que pueda calificarse de cualitativamente distinta a esas tres, a saber, una finalidad «reparadora» o algo así (a fin de cuentas, en la vertiente negativa, se habla de finalidad resarcitoria -de las sanciones civiles- como distinta de las finalidades de la pena). Por supuesto que un premio puro puede consistir en un reconocimiento que se exprese no mediante una medalla sino resarciendo por los perjuicios que sufrió el agente al realizar una conducta supererogatoria: la compensación misma sería un acto de reconocimiento; por supuesto que el incentivo (sea puro o esté incluido en una promesa de premio) también puede consistir en resarcir posibles daños, y no sólo en aportar beneficios netos; por supuesto que facilitar una conducta puede consistir precisamente en compensar los sacrificios que supondría realizarla. Si por esto fuera, la cuestión de la autonomía de las indemnizaciones ni siquiera habría de plantearse. Mis dudas surgen no sólo porque en realidad parecidos juegos medios/fines pueden también entablarse entre las otras tres categorías (puestos así, quizá ninguna podría verse como autónoma), sino porque no me parece en principio descabellado presentar la reparación de un perjuicio no merecido como una finalidad «en sí misma» (no sólo como instrumento para alguna de las otras tres finalidades), y buscar algunos casos paradigmáticos en los que se resarce no para premiar, ni incentivar, ni posibilitar/facilitar, sino para eso, para resarcir.

Pese a estas dudas, he decidido (¿provisionalmente?) no dar autonomía a esta finalidad, en parte porque desde luego muchas de esas «indemnizaciones positivas» efectivamente serían medios para los otros tres fines, pero sobre todo porque me parece que una de mis anteriores categorías podría dar cuenta de al menos buena parte de lo que quedara. Me refiero a la categoría de las facilitaciones. Las indemnizaciones de las que estoy hablando son «positivas», y se diferencian por tanto de las sanciones (negativas) civiles porque en estas últimas hay un autor de un ilícito civil (un deudor que incumple; o un causante de un cuasidelito o daño civil, un tortfeasor) a quien se «castiga» con la obligación de indemnizar (mejor dejar de lado la responsabilidad objetiva, en la que hablar de sanción negativa resulta ya más forzado, aunque, si se incluye, lo que aquí quiero decir no cambia). En las indemnizaciones positivas, en cambio, la reparación la realiza el Estado, porque no hay una conducta culpable (ni objetivamente responsable) de nadie (o de nadie a quien exigir la compensación), y muchas veces ni siquiera una conducta del destinatario de la compensación: aunque también pueden darse indemnizaciones positivas por los perjuicios derivados de la pro- 
pia conducta del destinatario (por considerarla valiosa, normalmente), los casos típicos son los de indemnizaciones por daños provocados por granizo, terremotos, inundaciones, terrorismo, guerras, u otros tipos de catástrofes. Dejando aparte la cuestión de si, en muchos casos, estas indemnizaciones no «operan sobre conductas» (mi planteamiento era el de medidas que operan sobre conductas para promocionar fines generales), la pregunta es: ¿Para qué finalidad quiere el Estado indemnizar, si «él no lo hizo»? ¿Es ésta una finalidad «autónoma»? Creo que esa finalidad, cuando no es instrumental para alguna de las otras tres, en la mayoría de los casos se puede reconducir y hacer coincidir con la de las facilitaciones. Al indemnizar, el Estado no quiere reconocer virtudes, ni incentivar directamente conductas, sólo quiere devolver al destinatario a la situación anterior al perjuicio sufrido. ¿Para qué? Si hablamos de conductas, para que al dañado le sea posible de nuevo realizar las mismas conductas que podía realizar antes, y con la misma facilidad (mucha o poca) que antes (y no con la dificultad añadida acarreada por el perjuicio que se quiere compensar). Esta finalidad es la misma que la de las facilitaciones. Cabe responder además (si no queremos hablar de conductas concretas): para hacer justicia, porque el daño sufrido es inmerecido (al menos en esa magnitud y consecuencias), por simple cuestión de igualdad, para restablecer las condiciones de igualdad de oportunidades -de posibilidades, de facilidades- con los demás que no sufrieron esa desgracia. Ese era el «fin general» a promocionar de algunas facilitaciones. Recuérdese el ejemplo de los discapacitados: la desgracia por la que se indemniza equivale a la desgracia inmerecida, de injustas consecuencias desigualitarias, de la discapacidad. Desigualdad (sea por discapacidad o por catástrofe) que se quiere corregir. 


\section{DOXA 23 (2000)}

